
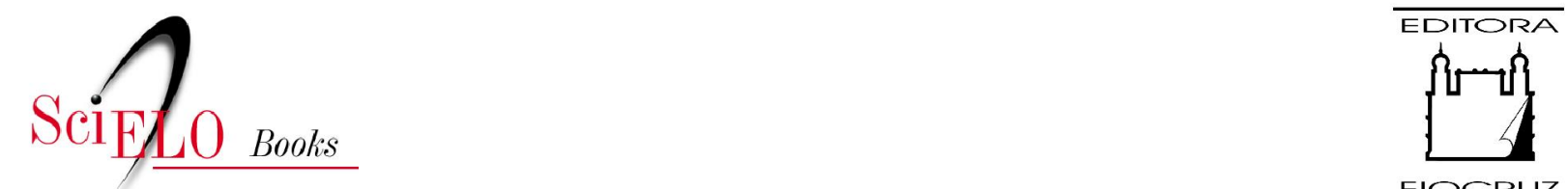

FIOCRUZ

\title{
3. Vamos criminalizar a proibição!
}

\author{
Marco Perduca
}

SciELO Books / SciELO Livros / SciELO Libros

PERDUCA, M. Vamos criminalizar a proibição! In: ACSELRAD, G. org. Avessos do prazer: drogas, Aids e direitos humanos [online]. 2nd ed. rev. and enl. Rio de Janeiro: Editora FIOCRUZ, 2005, pp. 51-63. ISBN: 978-85-7541-536-8. Available from: doi: 10.7476/9788575415368. Also available in ePUB from: http://books.scielo.org/id/bgqvf/epub/acselrad-9788575415368.epub

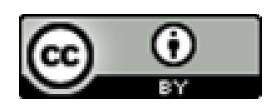

All the contents of this work, except where otherwise noted, is licensed under a Creative Commons Attribution $\underline{4.0 \text { International license. }}$

Todo o conteúdo deste trabalho, exceto quando houver ressalva, é publicado sob a licença Creative Commons Atribição 4.0.

Todo el contenido de esta obra, excepto donde se indique lo contrario, está bajo licencia de la licencia Creative Commons Reconocimento 4.0. 


\section{VAMOS CRIMINALIZAR}

A PROIBIÇÃO!*

Marco Perduca

Quanto mais se tenta dirigi-las

Com regras eproibiç̃es,

Mais pobres se tornam as vidas das pessoas,

Mais elas vivem em oposição.

Lao Tzu, Tao Te Ching 57, 2600 ca.

Errare bumanum est, perseverare diabolicus.

Este texto pretende discutir o tema da proibição e suas implicações em nosso cotidiano. Seu principal foco estará na proibição a 'drogas', na medida em que esta é a mais organizada, melhor estruturada e mais substancialmente fundada forma de proibição. Mas, também mencionarei rapidamente alguns outros tipos de proibições que têm um dramático e custoso impacto nas vidas de milhões, se não bilhões, de pessoas.

A proibição é sempre caracterizada por sua crítica e oposição, ou melhor, por seus críticos e opositores. Os proibicionistas às vezes se consideram investidos de forças metafísicas, com os meios para controlar perigosos fenômenos. Eles sempre se retratam como movidos por boa fé. Os proibicionistas nunca admitem que são, de fato, proibicionistas, na medida em que proibição é uma palavra que 'não soa bem'; é uma qualificação percebida como desagradável ou desajustada ou preconceituosa, atribuída com motivações políticas (e com razão) por quem sustenta outras visões sobre tais fenômenos.

Certamente, pode-se caracterizar a proibição como uma ideologia ou mesmo um dogma. Mostra-se apropriado acentuar suas perspectivas morais e éticas. Com toda a certeza, proibição é permeada por pensamentos e

\footnotetext{
* Tradução de Maria Lúcia Karam.
} 
ensinamentos religiosos ("Sou o Senhor teu Deus. Não deves ter outros deuses estranhos a mim”), assim como por diferentes - e, freqüentemente, ocultas - agendas políticas. Raramente a proibição é caracterizada como um conjunto de medidas sistematicamente incapazes de deslanchar.

O principal ponto para um debate sobre a proibição - um debate laico, livre de qualquer tipo de preconceito - só pode ser a falta de sucesso na implementação e na execução de medidas proibicionistas. Penso que a ineficácia resultante da proibição é o tópico crucial a ser levantado em tal debate. Discussões filosóficas e ideológicas certamente são importantes para preparar o campo para um confronto mais abrangente, mas, dada a urgência em enfrentar a proibição, começar pelas contingências pode se mostrar mais útil do que trabalhar sobre o fundo moral e as motivações éticas da proibição.

Discutir os catastróficos resultados do proibicionismo não só mostrará como proibir não funciona, como também tornará expostas as contradições daqueles que acreditam que, por trás da promoção de proibições, sempre existem boas intenções. Onde ficaria toda essa boa fé na reafirmação de um modelo que se traduz em leis e políticas que já falharam na produção dos resultados desejados?

A primeira tentativa de estruturar um conjunto de medidas destinadas a promover uma proibição coordenada em âmbito internacional data de 93 anos atrás, quando foi redigida a Convenção Internacional sobre o Ópio. ${ }^{1}$ No preâmbulo ao texto adotado em Haia em 23 de janeiro de 1912, os motivos inspiradores de tal ação são expostos sem ambigüidades. De fato, as delegações da Prússia, dos Estados Unidos da América, China, França, Reino Unido, Itália, Japão, Holanda, Pérsia, Portugal, Rússia e Sião afirmaram claramente sua determinação de "efetuar a supressão gradual do abuso de ópio, morfina e cocaína, assim como das drogas preparadas ou derivadas destas substâncias que levam ou podem levar a similares abusos", convencidos como estavam de que, naquele "esforço humanitário", [encontrariam] "a adesão unânime de todos os Estados interessados".

‘Esforço humanitário’ é uma expressão que encontraremos repetidas vezes no jargão proibicionista, na medida em que os proibicionistas sempre se retratam como um grupo de pessoas que se preocupa com os outros, mas, mais do que tudo, como um grupo de pessoas que acredita ter a apropriada, a VERDADEIRA cura ou solução para qualquer doença ou problema que nos rodeia (com efeito, eles sempre falam sobre 'abuso' de drogas, e nunca sobre 'uso').

\footnotetext{
1 http://www.austlii.edu.au/au/other/dfat/treaties/1920/20.html http://www.austlii.edu.au/au/other/dfat/treaties/1920/20.html
} 
Apesar das diferenças de culturas, tradições legais, formações étnicas ou religiosas, a proibição tem sido sempre considerada o único caminho 'correto' para cuidar do assunto. Claros exemplos daquele 'esforço humanitário' são as medidas impostas para 'regular' o divórcio, o aborto, orientações ou preferências sexuais, eutanásia, pesquisas sobre células-tronco, mas também fumo, jogo, prostituição, pornografia, blasfêmias, nudez ou arte de pichadores, para citar alguns. Governos de todas as partes do mundo adotaram a proibição como um modelo para limitar, conter ou 'regular' fenômenos considerados fora da normalidade.

Como dito, a proibição é quase sempre definida por seu oposto; mas como é definido esse oposto? Se a proibição é considerada uma qualificação ofensiva, degradante, (às vezes) injusta, etiquetar-se ou retratar-se como antiproibicionista é, ao contrário, algo mais desejável, ou mesmo fashion. Infelizmente, com muita freqüência, os anti-proibicionistas também tendem a se apresentar (representar) como o oposto da proibição, perdendo, dessa forma, uma grande oportunidade de elaborar uma definição de suas características e de suas propostas originais e alternativas.

Pode haver - e, efetivamente, há - muitas formas diferentes de definir anti-proibição ou anti-proibicionistas. Embora, em algum ponto da história da humanidade, pudesse ser útil estudar com mais profundidade e de formas metodologicamente apropriadas se há um fil rouge que possa verdadeiramente (re)construir a existência de um pensamento anti-proibicionista, dada a disseminada e disfarçada presença da proibição em nossas vidas, parece-me algo mais impositivo falar das implicações políticas que um conjunto de idéias e propostas anti-proibicionistas pode trazer para o público. Não obstante, se eu tivesse que identificar onde começou o pensamento anti-proibicionista, elegeria o pensador chinês Lao Tzu, um dos mais destacados taoístas, como o iniciador de uma tal 'escola de pensamento'.

De fato, há cerca de 2.600 anos, em um de seus escritos 'protolibertários', compilados no Tao Te Ching, Lao Tzu afirmou que "quanto mais proibições existirem, mais pobre será o povo".

Especialmente durante o Iluminismo, na França, no Reino Unido e em suas colônias americanas, muitos pensadores forjaram a idéia de que a limitação da liberdade pode trazer resultados negativos para o bem-estar das pessoas, mas raramente focalizaram sua atenção na proibição como o principal problema e da mesma forma incisiva com que o fez o pensador chinês. Os patriarcas fundadores dos Estados Unidos da América produziram algumas das mais abrangentes críticas às intromissões governamentais, redigindo do- 
cumentos como a Declaração da Independência, a Constituição e a Declaração de Direitos que se estendem por dois séculos e ainda permanecem como algumas das mais fascinantes peças de literatura (política) jamais escritas. $\mathrm{O}$ principal foco dos 'Patriarcas Fundadores' foi a falta de liberdade de expressão como o problema dos problemas.

A falta de debate, ou melhor, a imposição de uma agenda que arbitrária e autoritariamente exclui da discussão - proíbe - uma série de itens constitui a fonte de todas as proibições. O 'esforço humanitário' sempre se inspira na intenção de fazer o bem e, exatamente por isto, não pode - não deve - ser questionado, muito menos denunciado. O primeiro mandamento proibicionista sempre foi a imposição de sua própria autoridade e, eventualmente, o silenciar da oposição e da crítica.

Tal elemento foi particularmente evidenciado, por exemplo, em John Adams, ${ }^{2}$ que escreveu que "A liberdade não pode ser preservada sem um conhecimento geral por parte do povo, que tem o direito (...) e o desejo de saber (...) eles têm o direito, um inquestionável, inalienável, irrevogável, divino direito a esta mais temida e cobiçada espécie de conhecimento, ou seja, o caráter e a conduta de seus governantes”. O ‘divino’ direito de saber - e saber a fim de manter a própria liberdade - é crucial para a independência e a qualidade de vida. Infelizmente, tal exercício de crítica não pode ser dado como certo em nenhuma das sociedades baseadas - ou supostamente baseadas - em uma constituição liberal-democrática, escrita ou não. Ele é, certamente, a atividade mais combatida em regimes totalitários e autoritários.

A proibição empobrece todos os aspectos da vida humana, estabelecendo a presença de leis e políticas que promovem modelos éticos e morais baseados no controle, medidas que querem impor restrições dogmáticas à vida e à liberdade de bilhões de pessoas.

Se a anti-proibição se destina a ir contra tudo isso, ela só pode ser uma mistura de pensamentos políticos que, embora à primeira vista possam parecer díspares, quando melhor analisados podem, efetivamente, se combinar: o liberalismo clássico, o pensamento libertário, o pensamento progressista, o pensamento igualitário, o individualismo e o radicalismo, combinados em um mix que lida com temas concretos, tanto quanto lida com o problema 'corpo/mente'.

Sendo mais do que uma filosofia, a anti-proibição invade o domínio político. Em outras palavras, o anti-proibicionismo consiste em uma críti-

2 Dissertation on the Canon and Feudal Law (1765), que pode ser encontrada em http://oll.libertyfund.org/Home3/BookToCPage.php? recordID =0282. 
ca radical do status quo, uma crítica que gera propostas de reforma, que tenta enfrentar questões atualmente 'reguladas' por proibições, apontando medidas alternativas capazes de proporcionar caminhos mais eficientes e eficazes para 'governar' os diversos fenômenos. Anti-proibição, portanto, não significa anarquia.

Sendo, certamente, uma idéia revolucionária, a anti-proibição é uma forma de governo, de governança (se devemos usar uma dessas intraduzíveis expressões de que os especialistas gostam tanto). Livrar-se da proibição é uma forma de encontrar soluções para os desafios virtualmente colocados por todos os problemas. Isso foi verdade no passado, e é verdade hoje em dia, quando o mundo não tem fronteiras e leis e políticas nacionais sempre têm repercussão, impacto ou origem internacional.

Se eu tivesse que caracterizar em poucas palavras do que trata a antiproibição, enfatizaria, antes de tudo, o fato de que os antiproibicionistas (que, neste caso, se deve escrever sem o hífen) pretendem se dirigir às raízes dos problemas. Assim agindo, sempre acabam por identificar a proibição como $\mathrm{O}$ problema. Assim, a única resposta possível a essa espécie de conclusão analítica é a 'legalização' das condutas e/ou substâncias proibidas, a fim de regulálas de forma mais efetiva. Ergo, é de 'legalização' e não de 'liberalização' que os antiproibicionistas estão atrás.

Aqui, está em jogo mais do que uma mera questão de terminologia; com efeito, sempre que falamos de legalização e liberalização devemos caracterizar este tandem como uma dicotomia, isto é, uma dicotomia política. Pensadores liberais dos séculos XVII e XVIII, assim como os arquitetos constitucionais da era moderna, nos ensinaram que a liberdade é adquirida e salvaguardada com a adoção de regras e regulamentos que devem governar a sociedade, sempre que liberdades individuais são infringidas e violadas por outros indivíduos ou pelo próprio governo, e que, ao assim agir, o governo não está autorizado a impor um modelo de comportamento sobre outro. Qualquer outro.

Antiproibicionistas tentam conduzir as questões tendo em mente que somente a aplicação dos postulados do estado de direito é capaz de ensejar a efetividade de regulações, e que é sempre melhor permitir que as atividades humanas, inclusive as 'controvertidas', se realizem em um ambiente legal do que deixá-las se desenvolver à mercê do mundo ilegal. Como conseqüência desse raciocínio, os antiproibicionistas prezam muito o chamado princípio da legalidade e tentam apontar medidas e propostas que possam ajudar a sociedade a preservá-lo.

Tendo a legalização como objetivo final, uma aproximação gradual freqüentemente promovida - e adotada em algumas partes do mundo - é a 
progressiva despenalização de uma série de condutas (condenações menos severas, ou sanções 'administrativas', ou outras medidas alternativas), especialmente aquelas que podem ser consideradas ofensas não violentas. Uma progressiva 'despenalização' pode levar a uma descriminalização de facto, que, afinal, pode conduzir à plena legalização.

A legalização de comportamentos ou de produtos 'controvertidos' pode facilitar a administração dos fenômenos a eles concernentes em um ambiente de transparência, passível de controle público. Embora, a curto prazo, possa não refrear os problemas causados pela suposta 'periculosidade' do fenômeno, a longo prazo a legalização pode proporcionar opções mais viáveis para administrar as questões em jogo, ao mesmo tempo permitindo uma substancial economia de gastos públicos e a eventual realocação desses recursos para outros tipos de políticas.

No caso de drogas, embora possa não existir um modelo ou um caminho únicos para se perseguir a legalização, poder-se-ia imaginar um sistema regulador como os que já vêm atuando no controle de outras 'drogas', como o álcool e o tabaco, e dos problemas correlatos.

Vamos colocar o foco no que, de início, identifiquei como sendo possivelmente a mais organizada, estruturada e melhor fundada forma de proibição: aquela relativa a 'drogas'. Uso aspas ao me referir a drogas devido à falta de um consenso científico sobre o fato de todas as substâncias contidas nas três Convenções da ONU sobre Narcóticos e Substâncias Psicotrópicas ${ }^{3}$ poderem efetivamente ser consideradas drogas.

A Convenção Única de 1961 contém quatro 'tabelas' listando todas as substâncias que deveriam ser estritamente reguladas pelos países que ratificaram o documento. A Convenção proscreve as plantas necessárias à produção de narcóticos, da mesma forma que proscreve os produtos finais. Essa é mais uma razão por que é crucial manter a palavra 'drogas' entre aspas, na medida em que a Convenção vai além de proibir narcóticos e substâncias psicotrópicas. Os três documentos pretendem sistematizar uma forma de controle por meio da proibição da produção, do consumo e do comércio (tráfico) de um punhado de plantas e de dezenas de substâncias refinadas.

Muitas têm sido as leituras políticas das razões pelas quais, naquela específica conjuntura histórica, um grande grupo de países decidiu redigir um documento desse tipo. Uma lista de alguns dos principais eventos ocorridos naquele ano pode ser suficiente para resumir o que estava acontecendo no mun-

\footnotetext{
3 http://www.unodc.org/odccp/un_treaties_and_resolutions.html
} 
do 15 anos depois do fim da Segunda Guerra Mundial. Em 1961, estávamos no auge da Guerra Fria, com a Baía dos Porcos apenas acontecendo, a construção do Muro de Berlim em curso, Yuri Gagarin sendo o primeiro homem a visitar o espaço, a descolonização da África começando e a União Soviética tendo acabado de detonar uma bomba de hidrogênio de 58 megatons de potência em Novaya Zemlya (o maior aparato nuclear já detonado); o líder cubano Fidel Castro declarava ser marxista-leninista e que Cuba iria adotar o comunismo; um tribunal israelense de crimes de guerra condenava à morte Adolph Eichman por sua participação no holocausto judeu e, por último, o Plano Marshall chegava ao fim após ter distribuído mais de 12 bilhões de dólares de ajuda externa para reconstruir a Europa. Apesar disso tudo, amigos e inimigos decidiram se aliar para enfrentar um novo inimigo: 'drogas'.

Mais uma vez, no Preâmbulo à Convenção Única, nos dizem que "as Partes" estavam "preocupadas com a saúde e o bem-estar da humanidade" e, reconhecendo que o uso médico de drogas narcóticas continuava a ser "indispensável para o alívio da dor e do sofrimento e que devem ser adotadas as medidas necessárias para garantir a disponibilidade de drogas narcóticas para tal fim”, também afirmam que a adição a drogas narcóticas constituía "um sério mal para o indivíduo", trazendo "entranhado um perigo social e econômico para a humanidade". Assim, conscientes de seu dever de prevenir e combater esse "mal", aqueles países concordam em "classificar as diversas substâncias e efetivar, de modo rigoroso, a limitação da produção, do consumo e do comércio de todas aquelas substâncias”. A Convenção Única entrou em vigor em 13 de dezembro de 1964. Até aquela data 180 países a tinham ratificado.

Não contente com a Convenção de 1961, a 'comunidade internacional' se reuniu novamente em 1971 e em 1988 para redigir dois documentos adicionais. Com as tensões internacionais ainda bastante presentes por todo o mundo, mais uma vez amigos e inimigos encontraram tempo para adotar dois documentos adicionais para lutar contra as drogas, ajudar os usuários abusivos de drogas e criar um mundo mais seguro, purificado de todo o mal.

Todos esses elogiáveis objetivos são expostos, mais uma vez, nos Preâmbulos às Convenções, geralmente usados como declarações de princípios para apresentar os dispositivos legais dos documentos. De particular importância é o que abre a Convenção de 1988, a mais proibicionista das três. Com efeito, o parágrafo inicial explica como os signatários estão

profundamente preocupados com a magnitude e a tendência crescente da produção ilícita, da demanda e do tráfico de drogas narcóticas e substâncias psicotrópicas que representam uma grave ameaça à saúde e ao bem- 
estar dos seres humanos e afetam negativamente as bases econômicas, culturais e políticas da sociedade". ${ }^{4}$

A base da sociedade precisa ser salva, e a proibição é a resposta.

O Preâmbulo também traz à cena a figura (figura retórica, diga-se) das crianças. Com efeito, o parágrafo $2^{\circ}$ expressa as preocupações do mundo com a crescente penetração do tráfico ilícito de drogas narcóticas e substâncias psicotrópicas em vários grupos sociais, e particularmente com ofato de que, em muitas partes do mundo, crianças são usadas como um mercado de consumidores de drogas ilícitas e para os objetivos da produção, da distribuição e do comércio ilícitos de drogas narcóticas e substâncias psicotrópicas, o que embute um perigo de incalculável gravidade. (grifos meus)

Por último, drogas ainda "minam as economias legítimas e ameaçam a estabilidade, a segurança e a soberania dos Estados”. É difícil imaginar um inimigo mais perigoso.

Após dez anos da adoção da Convenção de 1988, sob o slogan "Um mundo livre de drogas, nós podemos fazê-lo”, cunhado para a ocasião pelo então diretor executivo do Escritório das Nações Unidas contra Drogas e Crime ${ }^{5}$, Pino Arlacchi, as Nações Unidas convocaram uma sessão especial da Assembléia Geral (Ungass) sobre narcóticos. ${ }^{6}$

Longe de apontar as derrotas que a guerra internacional contra as drogas estava sofrendo (produção crescente, aumento do consumo e fatais implicações de HIV/Aids relacionadas ao uso de drogas injetáveis), em sua declaração política, a Ungass reafirmou a necessidade de tratar as questões relacionadas a drogas em continuidade com o passado, promovendo a erradicação das plantações ilícitas como a atividade chave para a conquista de um mundo sem o mal das drogas. ${ }^{7}$ Para esse fim, deu-se grande ênfase a uma série de programas de redução de oferta, visando a erradicar as plantações de papoula e de coca no Sudeste Asiático e nos Andes. Outro aspecto crucial do plano-2008-mundo-livre-de-drogas-nós-podemos-fazê-lo foram os chamados projetos de 'redução de demanda' destinados a prevenir o 'abuso' de substâncias narcóticas.

\footnotetext{
${ }^{4}$ http://www.unodc.org/pdf/convention_1988_en.pdf

5 http://www.unodc.org. Embora em inglês o órgão referido tenha a denominação de United Nations Office on Drugs and Crime, cuja tradução em português, em princípio, deveria ser Escritório das Nações Unidas sobre Drogas e Crime, a denominação oficialmente adotada é a aqui utilizada - Escritório das Nações Unidas contra Drogas e Crime. Confira-se no site daquele órgão das Nações Unidas, para o Brasil: http://www.unodc.org/brazil/ (N. T.)

${ }^{6}$ http://www.un.org/ga/20special/

7 http://www.un.org/ga/20special/poldecla.htm
} 
Nenhuma menção às experiências de 'redução de danos' que estavam sendo exitosamente implementadas em diversos países, especialmente na Europa, nem um único painel dedicado à discussão de caminhos alternativos, como as experiências da Holanda ou da Itália de despenalização de facto ou de jure do uso pessoal de narcóticos ilícitos.

Em co-autoria com o Hon. Marco Cappato, ${ }^{8}$ o qual até o final de julho de 2004 teve assento no Parlamento Europeu pelos Radicais italianos, escrevi uma série de documentos ${ }^{9}$ para tentar levar à atenção da Comissão da ONU sobre Drogas Narcóticas uma crítica antiproibicionista do ponto de vista geral que a UNDCP estava privilegiando na preparação dos textos que seriam discutidos e adotados pela Ungass. Na circulação de nosso trabalho em 1997 e 1998, sempre encontramos uma posição firmemente proibicionista da liderança do Escritório da ONU em Viena. Atuando no interior do sistema das Nações Unidas há algum tempo, o que nos surpreendeu não foi o fato de a posição da ONU estar em desacordo com nossas propostas antiproibicionistas, mas, muito mais, a firme decisão de excluir argumentos críticos, na realidade, alternativos, de qualquer debate governamental ou não-governamental. "Não deves criticar" parecia ser o primeiro mandamento da era Arlacchi na UNDCP.

Os objetivos fixados pela Ungass 1998 eram tão impossíveis de serem atingidos que o chefe da UNDCP se considerou autorizado a usar de todos os meios necessários para alcançar o fim último de um mundo sem drogas. Da tessitura de notícias à cunhagem de negócios com os mais improváveis e ilegítimos parceiros, tais como a junta militar birmanesa ou os talibãs no Afeganistão, Pino Arlacchi estabeleceu um feudo em Viena que danificou a reputação e a efetividade da ONU em seus esforços de controlar drogas e prevenir crimes por todo o mundo.

O Partido Radical Transnacional, ${ }^{10}$ ONG filiada ao Conselho Econômico e Social da ONU que represento junto ao Escritório Central das Nações Unidas em Nova York, foi o único grupo a criticar o Sr. Arlacchi, desde o início de seu mandato em junho de 1997. ${ }^{11}$ Após anos de escândalos, ligações perigosas e desgovernos, o Escritório da ONU para Supervisão Interna de Serviços expediu um relatório oficial, expondo formalmente uma série de preocupações e apresentando algumas recomendações ao secretário-geral. ${ }^{12}$ Disso resultou a não indicação do Sr. Arlacchi para um segundo mandato.

\footnotetext{
8 www.marcocappato.it

9 http://www.radicalparty.org/antiprohibition/undcp.htm

${ }^{10}$ www.radicalparty.org

${ }^{11}$ http://coranet.radicalparty.org/pressreview/arlacchi1.php

${ }^{12}$ http://www.un.org/Depts/oios/reports/a56_689.pdf
} 
Em abril de 2003, o Escritório da ONU em Viena, apropriadamente renomeado Escritório contra Drogas e Crime (UNODC), ${ }^{13}$ convocou uma conferência de meio de período e um "Segmento Ministerial", ${ }^{14}$ para acompanhar o plano de ação adotado na Ungass. Embora, graças ao enfoque 'empresarial' do economista italiano Antonio Maria Costa, novo chefe do Escritório, ${ }^{15}$ o tom dos documentos convocatórios fosse menos beligerante do que os da Ungass 1998, mais uma vez não se dedicou virtualmente tempo algum para a avaliação - e muito menos para o julgamento - dos esforços internacionais para refrear a produção e o consumo de drogas, ${ }^{16}$ nem para a exposição da forma como os Estados individualmente estavam enfrentando o fenômeno.

A declaração final, adotada por representantes de 140 governos presentes em Viena, ${ }^{17}$ não só reafirmou o que havia sido acordado cinco anos antes, mas ainda expressou um novo tipo de preocupação, a preocupação

sobre políticas e atividades a favor da legalização de drogas narcóticas e substâncias psicotrópicas ilícitas que não estão de acordo com os tratados internacionais sobre controle de drogas e que podem pôr em perigo o regime internacional de controle de drogas.

Dado que nem um único país do mundo adotou ou promoveu políticas e atividades de apoio à legalização de drogas, aquela mensagem foi dirigida para alguns - só um, devo admitir - grupos que, efetivamente, ousaram reivindicar a legalização de drogas na ONU. Com o parágrafo acima mencionado, o Segmento Ministerial de 2003 não estava desferindo um golpe antecipado naqueles países que realmente estão adotando enfoques mais moderados na questão de drogas (eles estavam todos silenciosamente presentes em Viena e assinaram a declaração); o 'segmento' estava enviando uma clara mensagem para os 'legalizadores', retratando-os como um grupo de pessoas dedicadas a pôr em perigo o sistema internacional de controle de drogas, etiquetando-os como 'inimigos da causa'.

${ }^{13}$ Sobre a denominação em português do UNODC, veja-se a nota 4. (N. T.)

${ }^{14}$ http://www.undcp.org/cndministerial/index.html

15 Até 2003, a Itália era o maior doador do Escritório da ONU em Viena, daí a sucessão de diretores executivos italianos. No Segmento Ministerial de 2003, Paula J. Dobriansky, subsecretária para Assuntos Globais dos EUA, anunciou que a administração Bush, que lançara uma "dotação de 600 milhões de dólares, por três anos, para tratamento de aditos", estava também dobrando seu apoio para questões relacionados a drogas e crimes na ONU, empenhando algo como 24 milhões de dólares.

${ }^{16}$ Para uma cobertura crítica do Segmento Ministerial, veja-se LIAfax em http://www.radicalparty.org/ elist/archivio/corafax/cog16sn-04e.htm e http://www.radicalparty.org/elist/archivio/corafax/ $\operatorname{cog} 17$ sn-04e.htm

${ }^{17}$ http://www.unodc.org/pdf/document_2003-04-30_1.pdf 
Por mais falso que tal argumento possa ser, infelizmente ele se tornou um leit motif nas declarações emitidas pelo Sr. Costa desde a primavera de 2003. Com efeito, em diferentes ocasiões, o diretor executivo do UNODC posicionou-se publicamente, em diversos jornais italianos, dizendo que existe um lobby internacional pró-drogas que pretende legalizar os narcóticos para lucrar com o tráfico.

Embora possa haver um argumento legal para os 'legalizadores' processarem o Sr. Costa por difamação, ainda acredito que o confronto deva permanecer (mas, por quanto tempo?) com sua natureza política. O proibicionismo é um conjunto de leis e políticas que não deslancharam; na realidade, um conjunto de leis e políticas que falharam.

A prova desse resultado desastroso é produzida pela própria ONU, na série Tendências Globais das Drogas Ilícitas, publicada anualmente, ${ }^{18}$ assim como no Relatório Mundial sobre Drogas ${ }^{19}$ que, em teoria, deveria ser publicado a cada dois anos (mas que não é editado há mais de três anos, por toda sorte de razões). Fornecendo dados às vezes questionáveis e outros efetivamente questionados, ${ }^{20}$ falta, em todos esses documentos, uma análise aprofundada do fenômeno. Com efeito, parece que a ONU está absorvida por um esforço infinito de documentação que ignora totalmente, ou sistematicamente exclui, qualquer avaliação política da efetividade do atual sistema de 'controle de drogas'. ${ }^{21}$

Se, nos foros internacionais, países progressistas ou liberais, como o Canadá, a Suíça, o Reino Unido ou o Brasil, permanecem em silêncio, em casa, funcionários dos governos têm se juntado a especialistas, juristas, policiais, assim como a ONGs, para desenvolver argumentos críticos, apontando as falhas do enfoque de 'lei e ordem', sempre privilegiado no tratamento de questões relacionadas a drogas.

${ }_{18} \mathrm{http} / / /$ www.unodc.org

19 Cabe anotar que o Escritório da ONU em Viena deveria publicar o Relatório Mundial sobre Drogas de 2003 em setembro daquele ano; por uma série de razões, nenhuma delas comunicada oficialmente, o livro não foi publicado. Aparentemente, a falta de um enfoque científico do fenômeno, registrada na administração de Arlacchi, teria danificado a estrutura interna do Escritório e a reconstrução de alguma espécie de credibilidade analítica estaria demorando mais do que o esperado.

${ }^{20}$ Para uma leitura crítica dos dados da ONU disponíveis para o público, vejam-se as Atualizações de 2003, publicadas pela Liga Antiproibicionista Internacional, em http://www.radicalparty.org/ antiprohibition/report_2003/RAPPORTO.pdf

${ }^{21}$ Para uma crítica mais pontual sobre os últimos desenvolvimentos da política internacional sobre drogas, veja-se 'A first radical reform needed at the United Nations' [Uma primeira reforma radical necessária nas Nações Unidas], documento base do Partido Radical Transnacional para a $47^{\mathrm{a}} \mathrm{CND}$ ( $47^{\mathrm{a}}$ sessão da Comissão sobre Narcóticos\}, preparado em colaboração com a Liga Antiproibicionista Internacional, em http://servizi.radicalparty.org/ documents/index.php? func $=$ detail\&par $=3365$ 
Enquanto apenas um país, o Reino Unido, decidiu 'reenquadrar' os derivados da Cannabis, outros, como a Itália, com um referendum em 1993, como Portugal e Bélgica, com iniciativas legislativas em tempos mais recentes, despenalizaram o consumo pessoal de todas as substâncias. Por toda a Europa, mas também no Canadá, Austrália, Nova Zelândia e, evidentemente, na Suíça, projetos piloto da chamada 'redução de danos' evoluíram para programas desenvolvidos, que se tornaram a pedra angular de estratégias de 'redução de demanda' de governos locais e nacionais.

Mas, de que trata a 'redução de danos'? Danos causados por 'drogas'? Ou os provocados pela proibição? Tendo desmascarado, no início deste texto, a falta de bona fide que caracteriza o proibicionismo no alvorecer do terceiro milênio, a resposta mais pungente seria a última. E, se é este o caso, onde a proibição criou mais danos?

Há diferentes formas de listar as vítimas da proibição. A mais fácil poderia ser olhar os dados de várias publicações oficiais que fazem referência ao crescente número de usuários e 'dependentes', à redução da idade da primeira compra de drogas, à relação entre o uso de drogas injetáveis e a disseminação do HIV/Aids; certamente, poderíamos apontar para o crescimento financeiro das narcomáfias, sua influência nas políticas e nos políticos de dezenas de países, ou para as ligações entre drogas e terrorismo, documentadas por diversos centros de pesquisa independentes e também internacionais; poderíamos endossar os argumentos algumas vezes usados em campanhas eleitorais para expor o aumento dos gastos públicos na militarização da polícia, nos esforços para encarcerar o máximo possível de pessoas e no entupimento do trabalho dos juízes; poderíamos também quantificar a soma total de dinheiro gasto com campanhas de 'prevenção' ou de 'abstinência', inclusive identificando os 'confessionais' receptores daquele dinheiro.

Poderíamos fazer tudo isso ou poderíamos ir, mais profundamente, à raiz do problema, tentando sistematizar um tipo de crítica mais complexo e elaborado que leve em consideração o fato de a proibição, efetivamente, ir contra os direitos humanos, contra os direitos civis e políticos, assim como contra os direitos econômicos, sociais e culturais contidos nas Convenções Internacionais da $\mathrm{ONU},{ }^{22}$ ratificadas por todos os países democráticos que estão empreendendo uma 'guerra às drogas'.

No início deste texto, citei o adágio latino errare bumanum est, perseverare diabolicus. A sabedoria dos antigos deveria estar sempre conservada no fundo de

${ }^{23}$ Convenção Internacional sobre Direitos Econômicos, Sociais e Culturais, em http://www.unhchr.ch/ html/menu3/b/a_cescr.htm, e Convenção Internacional sobre Direitos Civis e Políticos em http:/ /www.unhchr.ch/html/menu3/b/a_ccpr.htm 
nossas mentes quando falamos sobre questões públicas ou quando as temos a nosso encargo. Especialmente se viemos das chamadas culturas neolatinas, os lemas latinos deveriam servir como um permanente caveat. Com a proibição estamos diante de uma diabólica perseverança na aplicação de políticas ineficazes que, como poderia surgir do estudo acima sugerido, estão também violando direitos humanos em uma escala disseminada e sistemática. Após quatro décadas de obstinação proibicionista, talvez tenha verdadeiramente amadurecido o tempo para se examinar a possibilidade de criminalizar a proibição, e não o que ela tenta regular.

A alavanca para um tal processo talvez pudesse ser um painel de juristas que poderiam argüir uma questão perante a Corte Internacional de Justiça, buscando a opinião consultiva do órgão mundial sobre a matéria.

Voluntários podem me contatar via e-mail: mperduca@antiprohibitionist.org 